\title{
Active Use and Engagement in an mHealth Initiative Among Young Men With Obesity: Mixed Methods Study
}

Alexander Wilhelm Gorny ${ }^{1,2,3}$, MBBS, MSc, MScPH; Wei Chian Douglas Chee ${ }^{1}$, MBBS; Falk Müller-Riemenschneider ${ }^{3,4,5}, \mathrm{MD}$

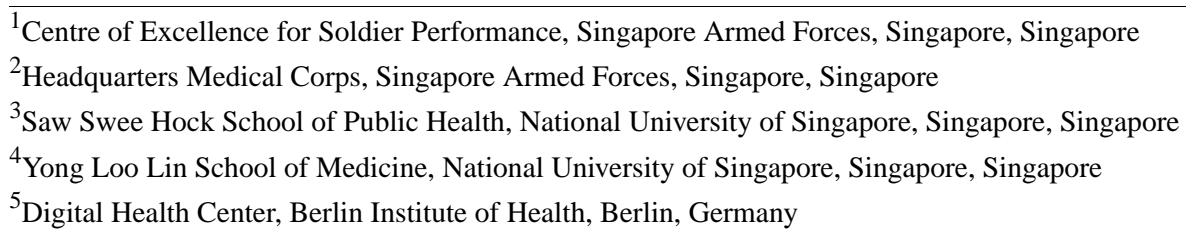

Corresponding Author:

Alexander Wilhelm Gorny, MBBS, MSc, MScPH

Centre of Excellence for Soldier Performance

Singapore Armed Forces

Pasir Laba Camp

Blk 130 \#03-09

Singapore, 637901

Singapore

Phone: 6581337238

Email: alexander_gorny@u.nus.edu

\section{Abstract}

Background: The effectiveness of mobile health (mHealth) approaches that employ wearable technology to promote physical activity have been the subject of concern due to the declining active use observed in trial settings.

Objective: To better contextualize active use, this study aimed to identify the barriers and enablers to engagement in a tracker-based mHealth initiative among young men who had recently completed a 19-week residential weight loss program.

Methods: A mixed methods study was conducted among 167 young men who had voluntarily enrolled in the national steps challenge (NSC), an mHealth physical activity promotion initiative, following a residential weight loss intervention. A subsample of 29 enrollees with a body mass index of 29.6 (SD 3.1) participated in semistructured interviews and additional follow-up assessments. Quantitative systems data on daily step count rates were used to describe active use. Qualitative data were coded and analyzed to elicit barriers and enablers to microlevel engagement in relation to the NSC, focusing on tracker and smartphone use. We further elicited barriers and enablers to macrolevel engagement by exploring attitudes and behaviors toward the NSC. Using triangulation, we examined how qualitative engagement in the NSC could account for quantitative findings on active use. Using integration of findings, we discussed how the mHealth intervention might have changed physical activity behavior.

Results: Among the 167 original enrollees, active use declined from $72(47 \%)$ in week 1 to 27 (17\%) in week 21. Mean daily step counts peaked in week 1 at 10,576 steps per day and were variable throughout the NSC. Barriers to engagement had occurred in the form of technical issues leading to abandonment, device switching, and offline tracking. Passive attitudes toward step counting and disinterest in the rewards had also prevented deeper engagement. Enablers of engagement included self-monitoring and coaching features, while system targets and the implicit prospect of reward had fostered new physical activity behaviors.

Conclusions: Our study showed that as the NSC is implemented in this population, more emphasis should be placed on technical support and personalized activity targets to promote lasting behavior change.

(JMIR Form Res 2022;6(1):e33798) doi: 10.2196/33798

\section{KEYWORDS}

mHealth; physical activity; health promoting financial incentives; weight loss maintenance; young men 


\section{Introduction}

Physical inactivity has been identified as a major risk factor for noncommunicable disease, early mortality, and increasing health care costs [1-3]. An active lifestyle is considered essential to weight loss and weight loss maintenance [4-7]. To improve physical activity, interventions should be tailored, goal-oriented, and multifaceted $[8,9]$. Mobile health (mHealth) technologies have offered new opportunities to achieve this in clinical care [10], population health [11,12], and consumer wellness settings [13]. Moreover, the mHealth approach is thought to improve access for groups who experience stigma during physical activity, such as persons with obesity [14,15].

Clinical mHealth interventions commonly employ self-monitoring, goal setting coaching prompts, as well as games and competitions to drive the motivation to exercise [16-18]. However, strong evidence is still lacking on the effectiveness of these approaches in young adults [19,20]. Conversely, mHealth programs that feature health promoting financial incentives (HPFIs) have been shown to provide powerful extrinsic motivation in young persons and adults [21-24]. However, the moral underpinnings of offering a reward in return for health behaviors have been the subject of debate $[25,26]$, and several studies have questioned whether HPFIs can produce sustained behavior change [27-30]. A recent paper has, however, characterized the relationship between physical activity behaviors and habits as bidirectional [31]. This means that once initiated by an HPFI [32,33], new behaviors such as activity tracking could reinforce physical activity habits and promote a virtuous cycle that persists even after the incentives have been discontinued.

One such mHealth initiative is the national steps challenge (NSC) which was first launched by Singapore's Health Promotion Board (HPB) in 2015 [34]. The NSC provided free access to a wrist-worn tracker that measured step counts and heart rate. Health points were awarded for attaining daily activity goals, and these could be converted to shopping or dining vouchers through a smartphone app, the Healthy 365 app. The system also featured back-end data linkages to accommodate 5 popular consumer tracking devices [35]. NSC incentives would lapse after 5 months, but enrollees would retain their trackers and free access to the Healthy 365 app.

In addition to its rollout to the general population, the NSC offered corporate programs to specific population groups. One such example was young men fulfilling national service obligations in the Singapore Armed Forces. During their basic training, all young men with a body mass index of $27.0 \mathrm{~kg} / \mathrm{m}^{2}$ or greater entered a 5-month residential weight loss program [36,37]. In December 2018, 1 intake of the residential program was offered to enroll in the NSC.

Many mHealth interventions experience a significant decline in active use [38], as reflected in quantitative systems data [39-41]. Decreasing [42] or insufficient engagement [43] have been cited as a possible explanation for such a decline. Current literature conceptualizes engagement with mHealth interventions as experiences and behaviors [44] that may vary between individuals and over time [45]. To better contextualize mHealth engagement, 2 complementary levels have been proposed: an operational microlevel that comprised moment-to-moment use and a strategic macrolevel where behavior change in pursuit of behavioral goals occurred [46].

Specifically in the areas of obesity management and weight maintenance, gaps in our understanding of mHealth use and engagement remain [47]. A review of 23 studies examining technology in the management of obesity highlighted that while user experience was critical to technology acceptance [48], only 2 studies reported user satisfaction as an outcome [49].

The NSC presented a unique opportunity for our team to build on previous studies involving the residential weight loss program $[50,51]$ and to aid our continuous efforts to promote physical activity in this group. In this mixed methods study, we therefore aimed to examine how qualitative engagement in the NSC could account for quantitative active use and discuss how the mHealth intervention might have changed physical activity behavior.

\section{Methods}

\section{Study Protocol}

Our mixed methods study protocol was approved by the Defence Science Organization of Singapore Armed Forces Institutional Review Board, reference 0010/2019. The quantitative component of this study examined longitudinal activity data, while the qualitative component comprised semistructured interviews. Multimedia Appendix 1 summarizes the phases, procedures and products of data collection and analysis [52]. Our methodological orientation was a grounded theory approach that focused on lived experiences of study participants. We employed a concurrent triangulation of methods strategy followed by data integration to coalesce our study findings. Our research team comprised 2 male, normal-weight military physicians, 1 of whom had experience in qualitative methods. Analyses and reporting were guided by a third author with expertise in physical activity promotion.

\section{Study Population and Recruitment}

In November 2018, 3 weeks before the end of the residential weight loss program, all 386 participants were invited to enroll in the NSC Season 4 (2018-2019) on a strictly voluntary basis. A cohort of 167 (43\%) young men expressed interest and were issued the NSC tracker 2 weeks later. In June 2019, 6 months after the initial enrollment and 1 month after the official end of the NSC, the research team invited a convenience sample of 48 cohort members working in 6 different large military camp complexes to participate in our study. To be deemed eligible, they had to be at least 21 years old and provide written informed consent to complete a survey, participate in semistructured interviews, and provide their mHealth data (Figure 1). The research team reached out to potential candidates via email to their immediate superiors. Study visits were scheduled for weekday afternoons at the nearest military medical facility. Participation was strictly voluntary, and information would be handled confidentially. No honoraria were paid, but time off from work was granted for the duration of the study visit. 
Figure 1. Recruitment for follow-up study, 6 months after enrollment into the national steps challenge.

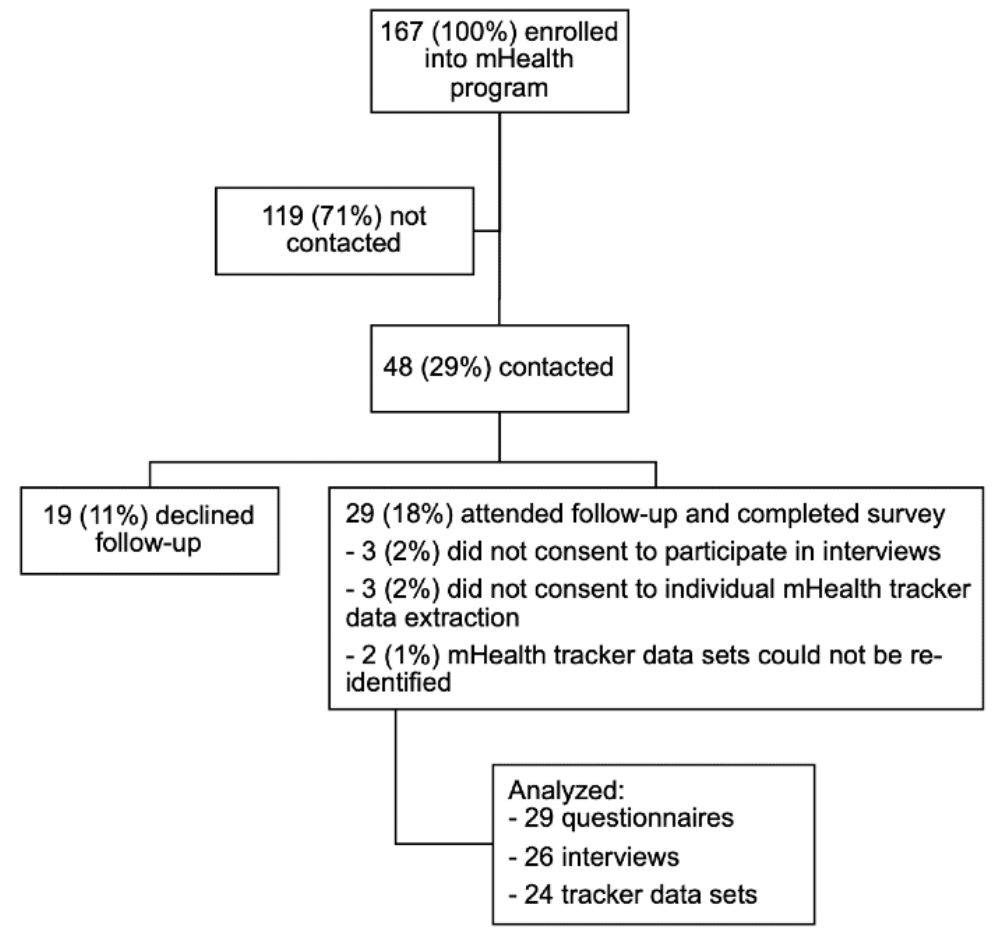

\section{Quantitative Component}

\section{Quantitative Data}

HPB Singapore provided our research team week-by-week summary data for the 167 cohort members. Active use was defined as a participant who registered at least 1 day with a nonzero step count for a given week. Days with zero steps were treated as missing data and excluded from the computation of average daily step counts. For the subset of consenting study participants, HPB released individually identifiable data that reflected step counts on a day-by-day level. Our questionnaire covered basic demographic information, the Behavioral Regulation in Exercise Questionnaire (BREQ-3) [53-55] and the International Physical Activity Questionnaire Short Form (IPAQ-SF) [56].

\section{Quantitative Analysis}

We retained HPB's definition of active use for the 167 cohort members and displayed weekly numbers of active users along with their average daily step counts graphically. To examine individually identifiable active use data more closely, we adopted a threshold of at least 1500 registered steps to indicate a valid day of active use [57]. In this group, nonvalid days of active use were treated as missing data and excluded from further reporting.

\section{Qualitative Component}

\section{Interviews}

Semistructured interviews followed a topic guide that was developed specifically for this study (Multimedia Appendix 2). Interviewers introduced themselves as medical professionals examining the effects of the NSC, soliciting open feedback, and exploring the lived experience. All interviews were conducted in a private room, recorded digitally, and transcribed by members of the research team.

\section{Qualitative Data Management}

First, 1 of the authors reviewed handwritten field notes and transcripts and coded key information according to the topic guide. In a second round of coding, interviewees' experiences using the trackers, synchronizing data, and responding to coaching prompts were coded as microlevel engagement. Interviewees' attitudes and behaviors that reflected involvement in the behavior change process (eg, related to daily goal setting, accumulation of health points, and redemption of rewards) were coded as macrolevel engagement. In a third round of coding, enablers were identified as circumstances that favored engagement or situations where engagement resulted in positive emotions or perceived benefits. Barriers were identified as circumstances that inhibited engagement or situations where engagement resulted in negative emotions or perceived loss.

\section{Data Triangulation, Mixing, and Integration}

In a triangulation of methods [58], we produced individual timeline plots to visually validate self-reported active use and categorize the duration of active use. A "short-term user" had accumulated less than 14 weeks of active use while a "sustained user" would have recorded or reported active use that was 14 weeks or longer. BREQ-3 scores, IPAQ-SF outcomes, anthropometric measurements, and barriers and enablers to engagement were reported by category of active use. Anthropometric data were compared using unpaired $t$ tests, while ordinal nonparametric BREQ-3 and IPAQ-SF data were analyzed using the Mood median test with $P=.05$ as the chosen level of statistical significance. Integration of findings provided a coherent narrative on active use and engagement before discussing changes in physical activity behavior. 
All quantitative analyses were conducted using Stata 13 (Stata Corp LLC). Qualitative data were collated and analyzed using NVivo 12 (QSR International). We used the Consolidated Criteria for Reporting Qualitative Research and the Good Reporting of a Mixed Methods Study checklists when compiling this manuscript $[59,60]$.

\section{Results}

\section{Quantitative Results}

mHealth system data showed that, in the first week, 72 (43\%) of the initial 167 enrolled users were actively recording step counts on a daily basis. On average, these users had walked 10,576 steps per day (Figure 2), excluding days of inactive use when zero steps had been registered. Thereafter, the number of active users declined steadily over the course of the NSC with only $27(17 \%)$ of users recording any steps in the final week.

From the 48 invited users, we recruited 29 participants, 21 to 25 years old, for the follow-up visit at 6 months (Table 1). However, 3 participants ( $\mathrm{P}, \mathrm{U}$, and $\mathrm{X}$ ) did not provide informed consent to contribute tracker data, and 2 participants ( $\mathrm{J}$ and $\mathrm{Z}$ ) who had provided consent could not be reidentified as registered users on the NSC. A total of 24 tracker data sets were thus available for detailed quantitative reporting and analysis. Of the 1357 person-days with nonzero step counts, 1070 (78.9\%) were designated as valid days of mHealth use (Multimedia Appendix 3).

Figure 2. Active users registered in the national steps challenge (gray bars) and their average daily step count (line) by week of enrollment. NSC: national steps challenge.

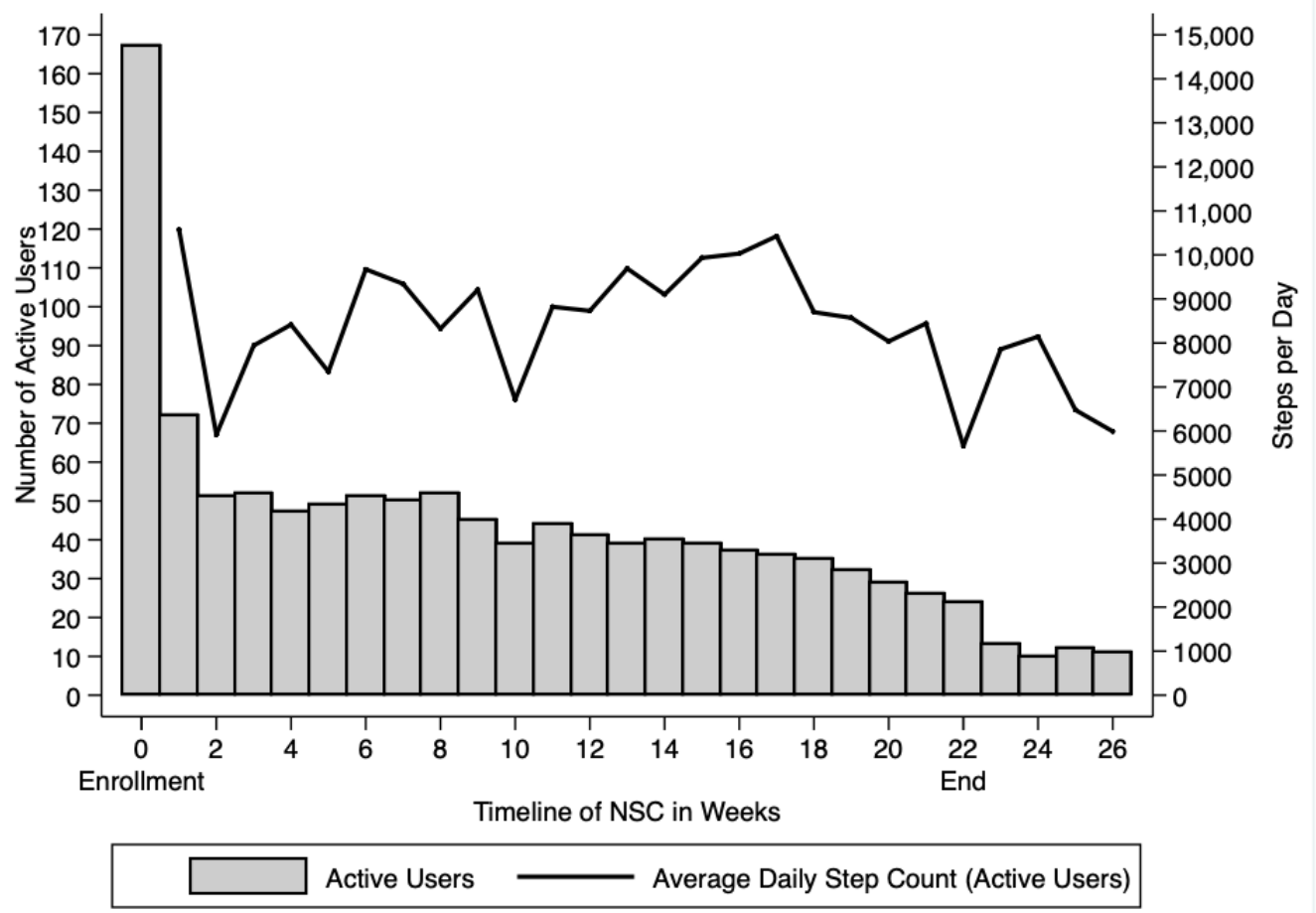


Table 1. Descriptive statistics for $n=29$ study participants.

\begin{tabular}{|c|c|c|}
\hline \multirow[t]{2}{*}{ Characteristics } & \multicolumn{2}{|l|}{ Values } \\
\hline & Sustained users $(\mathrm{n}=13), \mathrm{n}(\%)$ & Short-term users $(\mathrm{n}=16), \mathrm{n}(\%)$ \\
\hline \multicolumn{3}{|l|}{ Ethnicity } \\
\hline Chinese & $8(62)$ & $11(69)$ \\
\hline Malay & $2(15)$ & $1(6)$ \\
\hline Indian & $1(8)$ & $2(13)$ \\
\hline Others & $2(15)$ & $2(13)$ \\
\hline \multicolumn{3}{|l|}{ Education } \\
\hline Technical or "O" levels equivalent & $0(0)$ & $2(13)$ \\
\hline Polytechnic or "A" levels equivalent & $13(100)$ & $14(88)$ \\
\hline \multicolumn{3}{|l|}{ Smoking } \\
\hline Non-smoker and ex-smoker & $9(69)$ & $14(88)$ \\
\hline Smoker & $2(15)$ & $4(25)$ \\
\hline
\end{tabular}

Combined quantitative and qualitative data (Figure 3) allowed us to categorize participants A to L and AA as "sustained users" while participants $\mathrm{M}$ to $\mathrm{Z}, \mathrm{AB}$, and $\mathrm{AC}$ were categorized as "short-term users." Overall, sustained users expressed a higher level of agreement with BREQ-3 statements in the autonomous

spectrum of motivations to exercise (identified, integrated, and intrinsic), greater levels of activity recorded on the IPAQ-SF, and marginally lower levels of weight regain than those interviewees categorized as short-term users (Table 2). These differences, however, were not statistically significant.

Figure 3. Recorded (black dots) and self-reported (gray bars) duration of active use in $n=29$ participants; * denotes participants who did not consent to or failed in the retrieval of tracker data; ${ }^{\wedge}$ denotes participants who declined to interview. NSC: national steps challenge.

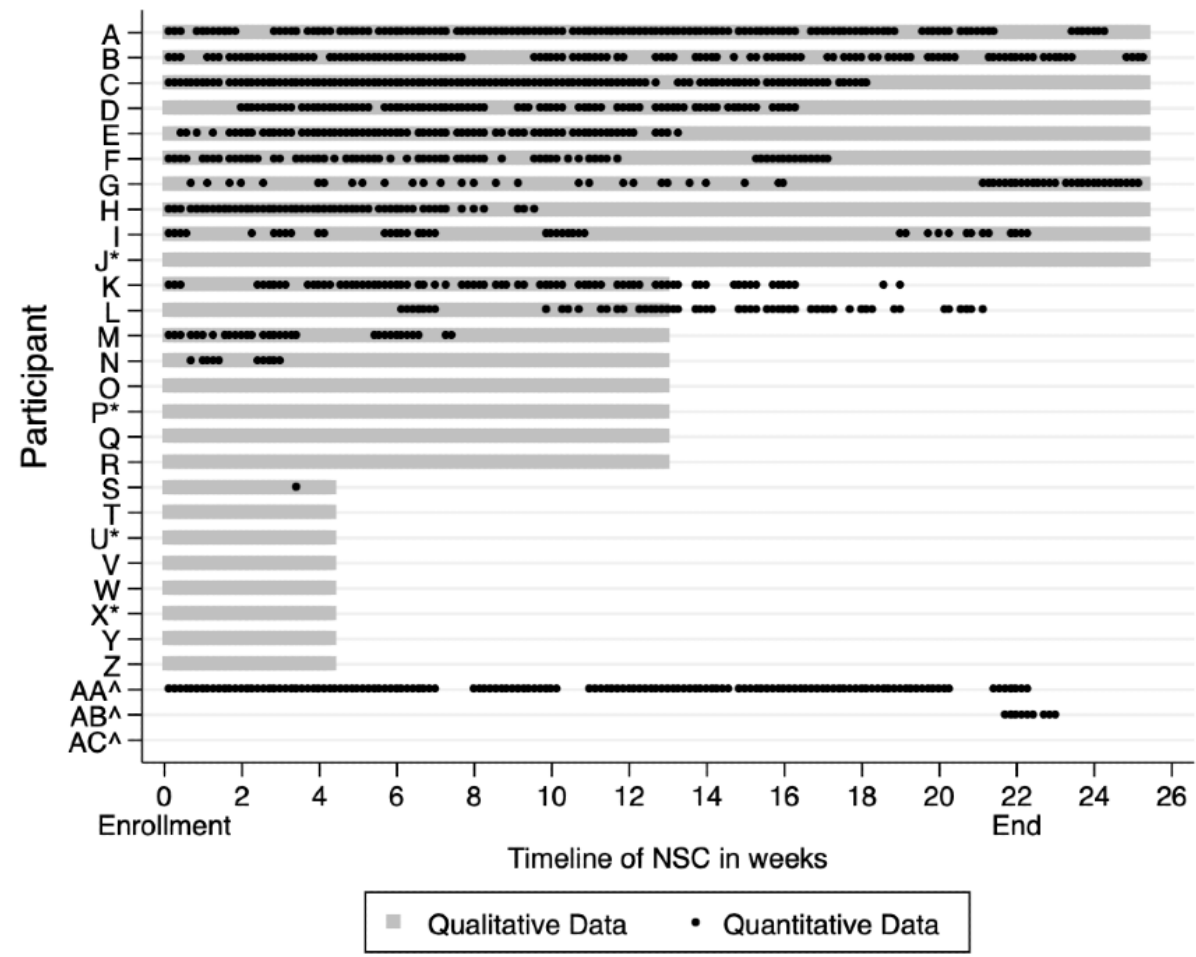


Table 2. Motivations to exercise, levels of activity, and anthropometric measures for $n=29$ study participants.

\begin{tabular}{|c|c|c|c|c|}
\hline Median measures & Overall $(n=29)$ & Sustained users $(n=13)$ & Short-term users $(n=16)$ & $P$ values \\
\hline \multicolumn{5}{|l|}{ BREQ-3 ${ }^{\mathrm{a}}$ median score (IQR) } \\
\hline Amotivation & $1.38(1-2)$ & $1.25(1-1.5)$ & $1.5(1-2.5)$ & $.26^{\#}$ \\
\hline External regulation & $2.5(2.25-3)$ & $2.75(2.5-3)$ & $2.25(2-3)$ & $.14^{\#}$ \\
\hline Introjected regulation & $3.25(2.75-3.63)$ & $3.25(3-3.75)$ & $3(2.25-3.25)$ & $.14^{\#}$ \\
\hline Identified regulation & $3.75(3.25-4.13)$ & $3.75(3.5-4.25)$ & $3.25(2.75-4)$ & $.28^{\#}$ \\
\hline Integrated regulation & $2.75(2.25-3.13)$ & $2.75(2.25-3.5)$ & $2.75(2.25-3)$ & $.74^{\#}$ \\
\hline Intrinsic motivation & $3.25(3-3.75)$ & $3.5(3.25-3.75)$ & $3(2.75-3.5)$ & $.14^{\#}$ \\
\hline \multicolumn{5}{|l|}{ IPAQ-SF ${ }^{b}$ median time in min/day (IQR) } \\
\hline Sitting & $360(270-540)$ & $360(300-480)$ & $420(210-600)$ & $.31^{\#}$ \\
\hline Walking & $130(50-385)$ & $140(105-350)$ & $60(0-420)$ & $.71^{\#}$ \\
\hline$M_{V P A}{ }^{c}$ & $15(0-47)$ & $34(9-51)$ & $9(0-30)$ & $.26^{\#}$ \\
\hline \multicolumn{5}{|l|}{ Mean weight measures, kg (SD) } \\
\hline Upon entry into residential program & $99.4(11.0)$ & $97.4(14.0)$ & $101(8.0)$ & $.40^{\wedge}$ \\
\hline Upon enrollment into NSC ${ }^{\mathrm{d}}$ & $83.8(10.4)$ & $81.9(13.7)$ & $85.4(6.6)$ & $.38^{\wedge}$ \\
\hline At time of study & $89.2(10.2)$ & $86.8(12.7)$ & $91.1(7.7)$ & $.26^{\wedge}$ \\
\hline \multicolumn{5}{|l|}{ Mean change in weight, $\mathrm{kg}$ (SD) } \\
\hline $\begin{array}{l}\text { From entry into residential program to NSC } \\
\text { enrollment }\end{array}$ & $-15.6(4.1)$ & $-15.5(4.9)$ & $-15.6(3.4)$ & $.94^{\wedge}$ \\
\hline From NSC enrollment to follow-up study & $5.3(4.5)$ & $4.9(5.6)$ & $5.7(3.5)$ & $.61^{\wedge}$ \\
\hline \multicolumn{5}{|l|}{ Mean BMI, kg/m² (SD) } \\
\hline Entry into residential program & $33.0(3.2)$ & $32.8(3.5)$ & $33.2(2.9)$ & $.72^{\wedge}$ \\
\hline NSC enrollment & $27.9(2.9)$ & $27.6(3.7)$ & $28.1(2.3)$ & $.64^{\wedge}$ \\
\hline Follow-up study & $29.6(3.1)$ & $29.3(3.8)$ & $30.0(2.5)$ & $.56^{\wedge}$ \\
\hline
\end{tabular}

${ }^{\mathrm{a} B R E Q-3: \text { Behavioral Regulation in Exercise Questionnaire } 3 .}$

bIPAQ-SF: International Physical Activity Questionnaire Short Form.

${ }^{\mathrm{c}}$ MVPA: moderate-to-vigorous physical activity.

${ }^{\mathrm{d}}$ NSC: national steps challenge.

${ }^{\#}$ Using the Mood median test with the Pearson chi-squared statistic.

${ }^{\wedge}$ Using the unpaired $t$ test.

\section{Qualitative Results}

Of the 29 participants, 3 ( $\mathrm{AA}, \mathrm{AB}$, and $\mathrm{AC}$ ) declined to participate in the qualitative segment of our study, meaning 26

semistructured interviews comprising a total of 6 hours and 27 minutes of recordings were available for analysis. An overview of barriers and enablers of microlevel and macrolevel engagement is provided in Table 3 . 
Table 3. Overview of barriers and enablers elicited from $n=26$ interviews.

\begin{tabular}{|c|c|c|}
\hline Barriers and enablers & $\begin{array}{l}\text { Sustained users } \\
(\mathrm{n}=12), \mathrm{n}(\%)\end{array}$ & $\begin{array}{l}\text { Short-term users } \\
(\mathrm{n}=14), \mathrm{n}(\%)\end{array}$ \\
\hline \multicolumn{3}{|l|}{ Microlevel barriers } \\
\hline Workplace safety regulations requiring clean wrists & $1(8)$ & $3(21)$ \\
\hline Removal of hard objects for contact sport & $2(17)$ & $1(7)$ \\
\hline Device failure, short battery life, frequent charging & $2(17)$ & $3(21)$ \\
\hline $\begin{array}{l}\text { Problems performing pairing of tracker with smartphone and problems synchronizing data through } \\
\text { cellular network }\end{array}$ & $3(25)$ & $7(50)$ \\
\hline Switch to a new tracker or wearable device & $8(67)$ & $9(64)$ \\
\hline \multicolumn{3}{|l|}{ Microlevel enablers } \\
\hline Use of tracker as a watch & $1(8)$ & $5(36)$ \\
\hline Visualization of cumulative step counts & $5(42)$ & $6(43)$ \\
\hline Convenient means of monitoring heart rate and exercise intensity & $4(33)$ & $2(14)$ \\
\hline Tracker-based coaching prompts & $4(33)$ & $3(21)$ \\
\hline \multicolumn{3}{|l|}{ Macrolevel barriers } \\
\hline Passive attitude toward step count tracking & $8(67)$ & $3(21)$ \\
\hline Sense of fairness or discomfort tracking incidental physical activity & $1(8)$ & $1(7)$ \\
\hline Psychological pressure to make steps count, be active, or attain goals & $1(8)$ & $1(7)$ \\
\hline Disinterest in the types of rewards & $4(33)$ & $5(36)$ \\
\hline \multicolumn{3}{|l|}{ Macrolevel enablers } \\
\hline Redeemed at least one reward & $10(83)$ & $4(29)$ \\
\hline Desire to maximize daily health points by adopting $\mathrm{NSC}^{\mathrm{a}}$ targets & $5(42)$ & $0(0)$ \\
\hline Personalized goal setting beyond system targets & $5(42)$ & $0(0)$ \\
\hline
\end{tabular}

${ }^{\mathrm{a}} \mathrm{NSC}$ : national steps challenge.

\section{Barriers to Microlevel Engagement}

A multitude of extrinsic and intrinsic factors led to the temporary removal or abandonment of the trackers. Some users overcame technical challenges simply by using the tracker in an offline mode thus forgoing data synchronization and rewards but retaining some of the basic features such as goal setting and self-monitoring. The chief reason for device switching was personal preference, given that more advanced devices generally offered additional functionality. Several users reported difficulty linking their new devices with the Healthy 365 platform, and only 1 sustained user reported that he had accumulated health points using his new tracker.

\section{Enablers of Microlevel Engagement}

Some users had been extrinsically motivated to don the tracker as it had become their primary means of telling time. Activity tracking and coaching features were intrinsically enabling, leading some users to report that tracking had become part of their exercise routine.

The tracker kind of makes you conscious of what you're doing. [Q: short-term user]

\section{Barriers to Macrolevel Engagement}

Some users had adopted a passive mindset in relation to the mHealth system, allowing steps to accrue throughout the day without monitoring their levels of activity. A few users only wore their trackers for structured exercise because they felt it was unfair to track incidental physical activity in the context of the NSC. Others experienced psychological pressure when using the mHealth system. Some users expressed disinterest in the rewards, and even a few sustained users felt they did not trigger any change in behavior. Other users openly questioned the morals of HPFIs.
[Concerning] rewards, I think it really depends on the person. Do they run because they want some reward or is it because of a more personal target? ... I would say I run because I like to run, not for anything else. [J: sustained user]

\section{Enablers of Macrolevel Engagement}

Some sustained users internalized the NSC's daily step target by developing interim targets that they could monitor throughout the day. Some described an autonomous process of setting personal step count or intensity targets that went beyond NSC thresholds. Others would even adopt a competitive mindset, either to outdo a previous level of activity or to outperform their peers. Most users reflected on HPFIs in transactional terms. 
This meant that the motivation to exercise and track their levels of activity diminished once the opportunity to earn vouchers had ceased. One participant, however, felt the incentives had outlived their purpose once he had become habituated to goal setting.

Right now, it's kind of ingrained in me. Right now, I'm not even thinking about the vouchers. Right now, it's just keeping fit. For me that's the greatest reward. [C: sustained user]

\section{Discussion}

\section{Main Findings}

Triangulation of methods uncovered that quantitative systems data alone painted an incomplete picture of active use among young men with obesity enrolled in the NSC. Our qualitative findings on barriers to microlevel and macrolevel engagement also demonstrated why a user might have failed to benefit from the NSC. Insights into enablers provided a mechanistic understanding of how the NSC initiated and inculcated new physical activity habits for a subset of users. Through further integration of findings, we shall now discuss the context of active use and engagement before examining how the NSC might have changed in physical activity behavior.

\section{Context of Active Use}

Given the variety of wearable tracking systems and mHealth apps available outside the NSC, it was not implausible that users would consider switching systems [61,62]. It is possible that upgrades and patches to operating systems might have disrupted back-end data linkages. Device switching and other forms of offline use would therefore have contributed an apparent decline in quantitative active use even though the desired behaviors were still being produced [63]. Given this context, it follows that the subsequent interpretation of engagement could still be considered internally consistent despite what a strict interpretation of objective active use might have suggested [64].

\section{Context of Engagement}

\section{Self-monitoring and Goal Setting}

Our findings have reinforced the notion that tracking devices on their own provided a feasible and acceptable means of self-monitoring and physical activity promotion [65]. While the NSC had prompted users to initiate, intensify, or extend physical activity [66], we suspect that generic performance targets might have also created a false ceiling in some sustained users [67]. Furthermore, it is plausible that inappropriate norms may have created negative feedback [68,69] or insecurity [70] among short-term users. Personalized goal setting, which has been a mainstay of physical activity promotion especially for weight loss maintenance, was exhibited by only a small number of users [71]. In this context, a shift in the goal setting strategy toward relative or personalized goals might enhance engagement.

\section{Health Promoting Financial Incentives}

At the macro level, health points had provided a virtual positive feedback loop that emulated customer loyalty program where membership, participation, and continued accrual of currency create their own intangible reward [72,73]. Even though only a minority of health points had been redeemed, interview data suggested that the system of HPFIs had communicated and reinforced a small but tangible external benefit of being physically active [74]. It was plausible that a less transactional or more attractive HPFI strategy (eg, a lottery [75] or endowment [76]) might have elicited higher enrollment, active use, and engagement.

\section{Lasting Behavior Change}

Self-monitoring behaviors are thought to diminish at the end of an intervention [77] while goal setting strategies are considered more durable [78]. Once HPFIs had been discontinued, some sustained users may have stopped tracking because of a loss of so-called habitual exercise instigation [79]. This means that bidirectional tracking and physical activity behaviors were still contingent on HPFIs. Alternatively, facing the prospect of a definite end point, some short-term and sustained users might have preemptively dissociated from the NSC by going offline or switching devices. These actions demonstrated an intent to extend self-monitoring and goal setting behaviors and are consistent with habit formation [80,81]. An apparent decline in active use should therefore be anticipated in population health settings.

\section{Study Implications}

Our study focused on a segment of the population that was not only at greater risk of the effects of inactivity, but also stood to reap real benefits from behavior change interventions such as the NSC [82]. These formative research findings have already aided our continuous efforts to promote physical activity in this group. We have also identified that pervasive offline use and device switching merit further investigation. Without due consideration for these phenomena, past studies that relied on quantitative mHealth data alone to categorize users [42] or to define nonuse attrition [43] might have inadvertently introduced misclassification biases that would have reduced the overall effect size or underestimated the public health impact of the interventions in question.

\section{Strengths and Limitations}

Objective tracker data were triangulated with subjective interview data to improve the accuracy and validity of our findings. By focusing on the barriers and enablers to engagement, we were able to examine and discuss the varied context of lived experiences engaging in the NSC.

Our study was affected by several limitations arising from the choice of study population and protocol. The participants were recruited in the context of national service, thus limiting the generalizability of our findings. By conducting semistructured interviews near the workplace, we may have inadvertently introduced information biases that would have favored public initiatives. Moreover, social desirability biases may have prevented enrollees with low mHealth use from participating in the study. 


\section{Conclusion}

Our study described how young men with obesity experienced an mHealth initiative promoting physical activity. We recognized that a decline in active use had occurred in the context of tracker abandonment, offline use, widespread device switching, and occasional dissatisfaction with the NSC.
Sustained users experienced engagement predominantly in the context of goal setting whereby HPFIs communicated the tangible benefit of a healthy lifestyle. As the NSC is implemented in this population, more emphasis should be placed on technical support and personalized activity targets to promote lasting behavior change.

\section{Acknowledgments}

Participation in the national steps challenge, season 4, was possible with the support of Health Promotion Board, Singapore. The Singapore Armed Forces funded this study and approved the final manuscript.

\section{Authors' Contributions}

AWG conceived this study and performed data collection, coding, and analyses before drafting the manuscript. WCDC assisted in data collection and coding. FMR supervised the research activities and reviewed the manuscript.

\section{Conflicts of Interest}

None declared.

\section{Multimedia Appendix 1}

Phases, procedures, and products of data collection and analysis.

[PNG File, 278 KB-Multimedia Appendix 1]

\section{Multimedia Appendix 2}

Topic guide and associated codes for the conduct and analysis of semistructured interviews.

[DOCX File , 28 KB-Multimedia Appendix 2]

\section{Multimedia Appendix 3}

Qualitative and quantitative data outlining use of the national step challenge among $\mathrm{n}=29$ study participants.

[DOCX File, 33 KB-Multimedia Appendix 3]

\section{References}

1. Blair SN. Physical inactivity: the biggest public health problem of the 21st century. Br J Sports Med 2009 Jan;43(1):1-2. [Medline: 19136507]

2. Kohl HW, Craig CL, Lambert EV, Inoue S, Alkandari JR, Leetongin G, et al. The pandemic of physical inactivity: global action for public health. Lancet 2012 Jul 21;380(9838):294-305. [doi: 10.1016/S0140-6736(12)60898-8] [Medline: 22818941]

3. Ding D, Lawson KD, Kolbe-Alexander TL, Finkelstein EA, Katzmarzyk PT, van Mechelen MW, Lancet Physical Activity Series 2 Executive Committee, et al. The economic burden of physical inactivity: a global analysis of major non-communicable diseases. Lancet 2016 Sep 24;388(10051):1311-1324. [doi: 10.1016/S0140-6736(16)30383-X] [Medline: $\underline{27475266}$ ]

4. Wareham NJ, van Sluijs EMF, Ekelund U. Physical activity and obesity prevention: a review of the current evidence. Proc Nutr Soc 2005 May;64(2):229-247. [doi: 10.1079/pns2005423] [Medline: 15960868]

5. Donnelly JE, Blair SN, Jakicic JM, Manore MM, Rankin JW, Smith BK. American College of Sports Medicine Position Stand. Appropriate physical activity intervention strategies for weight loss and prevention of weight regain for adults. Med Sci Sports Exerc 2009 Feb;41(2):459-471. [doi: 10.1249/MSS.0b013e3181949333] [Medline: 19127177]

6. Swift DL, McGee JE, Earnest CP, Carlisle E, Nygard M, Johannsen NM. The Effects of Exercise and Physical Activity on Weight Loss and Maintenance. Prog Cardiovasc Dis 2018;61(2):206-213. [doi: 10.1016/j.pcad.2018.07.014] [Medline: 30003901]

7. Petridou A, Siopi A, Mougios V. Exercise in the management of obesity. Metabolism 2019 Mar;92:163-169. [doi: 10.1016/j.metabol.2018.10.009] [Medline: 30385379]

8. Müller-Riemenschneider F, Reinhold T, Nocon M, Willich SN. Long-term effectiveness of interventions promoting physical activity: a systematic review. Prev Med 2008 Oct;47(4):354-368. [doi: 10.1016/j.ypmed.2008.07.006] [Medline: 18675845]

9. van Sluijs EMF, McMinn AM, Griffin SJ. Effectiveness of interventions to promote physical activity in children and adolescents: systematic review of controlled trials. Br J Sports Med 2008 Aug;42(8):653-657. [Medline: 18685076] 
10. Direito A, Carraça E, Rawstorn J, Whittaker R, Maddison R. mHealth Technologies to Influence Physical Activity and Sedentary Behaviors: Behavior Change Techniques, Systematic Review and Meta-Analysis of Randomized Controlled Trials. Ann Behav Med 2017 Apr;51(2):226-239. [doi: 10.1007/s12160-016-9846-0] [Medline: 27757789]

11. Duncan MJ, Brown WJ, Mummery WK, Vandelanotte C. 10,000 Steps Australia: a community-wide eHealth physical activity promotion programme. Br J Sports Med 2018 Jul;52(14):885-886. [doi: 10.1136/bjsports-2017-097625] [Medline: $\underline{28870978]}$

12. Patel DN, Nossel C, Patricios J, Maboreke J. Bright spots, physical activity investments that work: Vitality Active Rewards-a smartphone app that incentivises programme members to be physically active. Br J Sports Med 2018 Dec;52(23):1494-1496. [doi: 10.1136/bjsports-2018-099271] [Medline: 29934427]

13. Faiola A, Holden RJ. Consumer Health Informatics: Empowering Healthy-Living-Seekers Through mHealth. Prog Cardiovasc Dis 2017;59(5):479-486. [doi: 10.1016/j.pcad.2016.12.006] [Medline: 28038910]

14. Vartanian LR, Novak SA. Internalized societal attitudes moderate the impact of weight stigma on avoidance of exercise. Obesity (Silver Spring) 2011 Apr;19(4):757-762 [FREE Full text] [doi: 10.1038/oby.2010.234] [Medline: 20948515]

15. Vandelanotte C, Müller AM, Short CE, Hingle M, Nathan N, Williams SL, et al. Past, Present, and Future of eHealth and mHealth Research to Improve Physical Activity and Dietary Behaviors. J Nutr Educ Behav 2016 Mar;48(3):219-228.e1. [doi: 10.1016/j.jneb.2015.12.006] [Medline: 26965100]

16. Eckerstorfer LV, Tanzer NK, Vogrincic-Haselbacher C, Kedia G, Brohmer H, Dinslaken I, et al. Key Elements of mHealth Interventions to Successfully Increase Physical Activity: Meta-Regression. JMIR Mhealth Uhealth 2018 Nov 12;6(11):e10076 [FREE Full text] [doi: 10.2196/10076] [Medline: 30425028]

17. Conroy DE, Yang C, Maher JP. Behavior change techniques in top-ranked mobile apps for physical activity. Am J Prev Med 2014 Jun;46(6):649-652. [doi: 10.1016/j.amepre.2014.01.010] [Medline: 24842742]

18. Edwards EA, Lumsden J, Rivas C, Steed L, Edwards LA, Thiyagarajan A, et al. Gamification for health promotion: systematic review of behaviour change techniques in smartphone apps. BMJ Open 2016 Oct 04;6(10):e012447 [FREE Full text] [doi: 10.1136/bmjopen-2016-012447] [Medline: 27707829]

19. Ridgers ND, McNarry MA, Mackintosh KA. Feasibility and Effectiveness of Using Wearable Activity Trackers in Youth: A Systematic Review. JMIR Mhealth Uhealth 2016 Nov 23;4(4):e129 [FREE Full text] [doi: 10.2196/mhealth.6540] [Medline: 27881359]

20. Milne-Ives M, Lam C, De Cock C, Van Velthoven MH, Meinert E. Mobile Apps for Health Behavior Change in Physical Activity, Diet, Drug and Alcohol Use, and Mental Health: Systematic Review. JMIR Mhealth Uhealth 2020 Mar 18;8(3):e17046 [FREE Full text] [doi: 10.2196/17046] [Medline: 32186518]

21. Corepal R, Tully MA, Kee F, Miller SJ, Hunter RF. Behavioural incentive interventions for health behaviour change in young people (5-18 years old): A systematic review and meta-analysis. Prev Med 2018 May;110:55-66. [doi: 10.1016/j.ypmed.2018.02.004] [Medline: 29432789]

22. Barte JCM, Wendel-Vos GCW. A Systematic Review of Financial Incentives for Physical Activity: The Effects on Physical Activity and Related Outcomes. Behav Med 2017;43(2):79-90. [doi: 10.1080/08964289.2015.1074880] [Medline: 26431076]

23. Hajat C, Hasan A, Subel S, Noach A. The impact of short-term incentives on physical activity in a UK behavioural incentives programme. NPJ Digit Med 2019;2:91 [FREE Full text] [doi: 10.1038/s41746-019-0164-3] [Medline: 31531396]

24. Hafner M, Pollard J, Van Stolk C. Incentives and Physical Activity: An Assessment of the Association Between Vitality's Active Rewards with Apple Watch Benefit and Sustained Physical Activity Improvements. Rand Health Q 2020 Jun;9(1):4 [FREE Full text] [Medline: 32742746$]$

25. Giles EL, Sniehotta FF, McColl E, Adams J. Acceptability of financial incentives for health behaviour change to public health policymakers: a qualitative study. BMC Public Health 2016 Sep 15;16:989 [FREE Full text] [doi: 10.1186/s12889-016-3646-0] [Medline: 27633661]

26. Hoskins K, Ulrich CM, Shinnick J, Buttenheim AM. Acceptability of financial incentives for health-related behavior change: An updated systematic review. Prev Med 2019 Sep;126:105762. [doi: 10.1016/j.ypmed.2019.105762] [Medline: 31271816]

27. Luong MN, Hall M, Bennell KL, Kasza J, Harris A, Hinman RS. The Impact of Financial Incentives on Physical Activity: A Systematic Review and Meta-Analysis. Am J Health Promot 2021 Feb;35(2):236-249. [doi: 10.1177/0890117120940133] [Medline: $\underline{\text { 32672050] }}$

28. Strohacker K, Galarraga O, Williams DM. The impact of incentives on exercise behavior: a systematic review of randomized controlled trials. Ann Behav Med 2014 Aug;48(1):92-99 [FREE Full text] [doi: 10.1007/s12160-013-9577-4] [Medline: 24307474]

29. Finkelstein EA, Haaland BA, Bilger M, Sahasranaman A, Sloan RA, Nang EEK, et al. Effectiveness of activity trackers with and without incentives to increase physical activity (TRIPPA): a randomised controlled trial. Lancet Diabetes Endocrinol 2016 Dec;4(12):983-995. [doi: 10.1016/S2213-8587(16)30284-4] [Medline: 27717766]

30. Mitchell MS, Orstad SL, Biswas A, Oh PI, Jay M, Pakosh MT, et al. Financial incentives for physical activity in adults: systematic review and meta-analysis. Br J Sports Med 2019 May 15:1259-1268. [doi: 10.1136/bjsports-2019-100633] [Medline: $\underline{31092399]}$ 
31. Feil K, Allion S, Weyland S, Jekauc D. A Systematic Review Examining the Relationship Between Habit and Physical Activity Behavior in Longitudinal Studies. Front Psychol 2021;12:626750 [FREE Full text] [doi: 10.3389/fpsyg.2021.626750] [Medline: $\underline{33746848]}$

32. Hagger MS. Habit and physical activity: Theoretical advances, practical implications, and agenda for future research. Psychology of Sport and Exercise 2019 May;42:118-129. [doi: 10.1016/j.psychsport.2018.12.007]

33. Gardner B, Rebar AL, Lally P. 'Habitually deciding' or 'habitually doing'? A response to Hagger (2019). Psychology of Sport and Exercise 2020 Mar 1;47:101539. [doi: 10.1186/s40900-015-0008-5]

34. Yao J, Tan CS, Chen C, Tan J, Lim N, Müller-Riemenschneider F. Bright spots, physical activity investments that work: National Steps Challenge, Singapore: a nationwide mHealth physical activity programme. Br J Sports Med 2020 Sep;54(17):1047-1048. [doi: 10.1136/bjsports-2019-101662] [Medline: $\underline{31857340]}$

35. Step-by-Step Guide: How to Sign Up for National Steps Challenge? Season 4. Health Promotion Board of Singapore. 2019. URL: https://www.healthhub.sg/sites/assets/Assets/Programs/NSC4-MainChallenge/pdfs/

Step_by_Step_Guide_for_Main_Challenge_2019.pdf [accessed 2021-09-02]

36. Lee L, Kumar S, Leong LC. The impact of five-month basic military training on the body weight and body fat of 197 moderately to severely obese Singaporean males aged 17 to 19 years. Int J Obes Relat Metab Disord 1994 Feb;18(2):105-109. [Medline: 8148923$]$

37. Lim CL, Lee LK. The effects of 20 weeks basic military training program on body composition, VO2max and aerobic fitness of obese recruits. J Sports Med Phys Fitness 1994 Sep;34(3):271-278. [Medline: 7830391]

38. Eysenbach G. The law of attrition. J Med Internet Res 2005;7(1):e11 [FREE Full text] [doi: 10.2196/jmir.7.1.e11] [Medline: 15829473]

39. Kelders SM, Kok RN, Ossebaard HC, Van Gemert-Pijnen JEWC. Persuasive system design does matter: a systematic review of adherence to web-based interventions. J Med Internet Res 2012 Nov 14;14(6):e152 [FREE Full text] [doi: 10.2196/jmir.2104] [Medline: 23151820]

40. Sieverink F, Kelders SM, van Gemert-Pijnen JEWC. Clarifying the Concept of Adherence to eHealth Technology: Systematic Review on When Usage Becomes Adherence. J Med Internet Res 2017 Dec 06;19(12):e402 [FREE Full text] [doi: 10.2196/jmir.8578] [Medline: 29212630]

41. Mitchell M, Lau E, White L, Faulkner G. Commercial app use linked with sustained physical activity in two Canadian provinces: a 12-month quasi-experimental study. Int J Behav Nutr Phys Act 2020 Feb 25;17(1):24 [FREE Full text] [doi: 10.1186/s12966-020-00926-7] [Medline: 32098625]

42. Guertler D, Vandelanotte C, Kirwan M, Duncan MJ. Engagement and Nonusage Attrition With a Free Physical Activity Promotion Program: The Case of 10,000 Steps Australia. J Med Internet Res 2015;17(7):e176 [FREE Full text] [doi: 10.2196/jmir.4339] [Medline: 26180040]

43. Edney S, Ryan JC, Olds T, Monroe C, Fraysse F, Vandelanotte C, et al. User Engagement and Attrition in an App-Based Physical Activity Intervention: Secondary Analysis of a Randomized Controlled Trial. J Med Internet Res 2019 Nov 27;21(11):e14645 [FREE Full text] [doi: 10.2196/14645] [Medline: 31774402]

44. Perski O, Blandford A, West R, Michie S. Conceptualising engagement with digital behaviour change interventions: a systematic review using principles from critical interpretive synthesis. Transl Behav Med 2016 Dec 13:254-267. [doi: 10.1007/s13142-016-0453-1] [Medline: 27966189]

45. Yardley L, Spring BJ, Riper H, Morrison LG, Crane DH, Curtis K, et al. Understanding and Promoting Effective Engagement With Digital Behavior Change Interventions. Am J Prev Med 2016 Nov;51(5):833-842. [doi: 10.1016/j.amepre.2016.06.015] [Medline: 27745683]

46. Short CE, DeSmet A, Woods C, Williams SL, Maher C, Middelweerd A, et al. Measuring Engagement in eHealth and mHealth Behavior Change Interventions: Viewpoint of Methodologies. J Med Internet Res 2018 Nov 16;20(11):e292 [FREE Full text] [doi: 10.2196/jmir.9397] [Medline: 30446482]

47. Asbjørnsen RA, Smedsrød ML, Solberg Nes L, Wentzel J, Varsi C, Hjelmesæth J, et al. Persuasive System Design Principles and Behavior Change Techniques to Stimulate Motivation and Adherence in Electronic Health Interventions to Support Weight Loss Maintenance: Scoping Review. J Med Internet Res 2019 Jun 21;21(6):e14265 [FREE Full text] [doi: 10.2196/14265] [Medline: 31228174$]$

48. Davis FD. User acceptance of information technology: system characteristics, user perceptions and behavioral impacts. International Journal of Man-Machine Studies 1993 Mar;38(3):475-487. [doi: 10.1006/imms.1993.1022]

49. Shannon HH, Joseph R, Puro N, Darrell E. Use of Technology in the Management of Obesity: A Literature Review. Perspect Health Inf Manag 2019;16(Fall):1c [FREE Full text] [Medline: 31908626]

50. Shi H, Jiang B, Wei Sim JD, Chum ZZ, Ali NB, Toh MH. Factors associated with obesity: a case-control study of young adult Singaporean males. Mil Med 2014 Oct;179(10):1158-1165. [doi: 10.7205/MILMED-D-14-00064] [Medline: 25269135]

51. Gorny AW, Low MC, Sayampanathan AA, Shiraz F, Müller-Riemenschneider F. Motivations to exercise in young men following a residential weight loss programme conducted in National Service - a mixed methods study. BMC Public Health 2021 Feb 17;21(1):370 [FREE Full text] [doi: 10.1186/s12889-021-10373-z] [Medline: 33596886]

52. Ivankova NV, Creswell JW, Stick SL. Using Mixed-Methods Sequential Explanatory Design: From Theory to Practice. Field Methods 2016 Jul 21;18(1):3-20. [doi: 10.1177/1525822x05282260] 
53. Mullan E, Markland D, Ingledew DK. A graded conceptualisation of self-determination in the regulation of exercise behaviour: Development of a measure using confirmatory factor analytic procedures. Personality and Individual Differences 1997 Nov;23(5):745-752. [doi: 10.1016/s0191-8869(97)00107-4]

54. Ryan RM, Deci EL. Self-determination theory and the facilitation of intrinsic motivation, social development, and well-being. Am Psychol 2000 Jan;55(1):68-78. [doi: 10.1037//0003-066x.55.1.68] [Medline: 11392867]

55. Markland D, Tobin V. A modification to the behavioural regulation in exercise questionnaire to include an assessment of amotivation. Journal of Sport and Exercise Psychology 2004;26(2):191-196. [doi: 10.1123/jsep.26.2.191]

56. Craig CL, Marshall AL, Sjöström M, Bauman AE, Booth ML, Ainsworth BE, et al. International physical activity questionnaire: 12-country reliability and validity. Med Sci Sports Exerc 2003 Aug;35(8):1381-1395. [doi: 10.1249/01.MSS.0000078924.61453.FB] [Medline: 12900694]

57. Tudor-Locke C, Barreira TV, Schuna JM. Comparison of step outputs for waist and wrist accelerometer attachment sites. Med Sci Sports Exerc 2015 Apr;47(4):839-842. [doi: 10.1249/MSS.0000000000000476] [Medline: 25121517]

58. Polit D, Beck C. Nursing research: Generating and assessing evidence for nursing practice (8th Edition). Philadelphia, PA, US: Wolters Kluwer; 2008:553-555.

59. Tong A, Sainsbury P, Craig J. Consolidated criteria for reporting qualitative research (COREQ): a 32-item checklist for interviews and focus groups. Int J Qual Health Care 2007 Dec;19(6):349-357 [FREE Full text] [doi: 10.1093/intqhc/mzm042] [Medline: 17872937]

60. O'Cathain A, Murphy E, Nicholl J. The quality of mixed methods studies in health services research. J Health Serv Res Policy 2008 Apr;13(2):92-98. [doi: 10.1258/jhsrp.2007.007074] [Medline: 18416914]

61. Ometov A, Shubina V, Klus L, Skibińska J, Saafi S, Pascacio P, et al. A Survey on Wearable Technology: History, State-of-the-Art and Current Challenges. Computer Networks 2021 Jul;193:108074. [doi: 10.1016/j.comnet.2021.108074]

62. Aitken M, Clancy B, Nass D. The growing value of digital healthvidence and impact on human health and the healthcare system. IQVIA Institute for Human Data Science Nov. 2017 Nov 07. URL: https://www.iqvia.com/insights/the-iqvia-institute/ reports/the-growing-value-of-digital-health [accessed 2021-11-14]

63. Alshurafa N, Jain J, Alharbi R, Iakovlev G, Spring B, Pfammatter A. Is More Always Better?: Discovering Incentivized mHealth Intervention Engagement Related to Health Behavior Trends. Proc ACM Interact Mob Wearable Ubiquitous Technol 2018 Dec;2(4):1-45 [FREE Full text] [doi: 10.1145/3287031] [Medline: 32318650]

64. Scherer EA, Ben-Zeev D, Li Z, Kane JM. Analyzing mHealth Engagement: Joint Models for Intensively Collected User Engagement Data. JMIR Mhealth Uhealth 2017 Jan 12;5(1):e1 [FREE Full text] [doi: 10.2196/mhealth.6474] [Medline: 28082257]

65. Asbjørnsen RA, Wentzel J, Smedsrød ML, Hjelmesæth J, Clark MM, Solberg Nes L, et al. Identifying Persuasive Design Principles and Behavior Change Techniques Supporting End User Values and Needs in eHealth Interventions for Long-Term Weight Loss Maintenance: Qualitative Study. J Med Internet Res 2020 Nov 30;22(11):e22598 [FREE Full text] [doi: 10.2196/22598] [Medline: 33252347]

66. Schüll ND. Data for life: Wearable technology and the design of self-care. BioSocieties 2016 Oct 13;11(3):317-333. [doi: 10.1057/biosoc.2015.47]

67. Swann C, Rosenbaum S, Lawrence A, Vella SA, McEwan D, Ekkekakis P. Updating goal-setting theory in physical activity promotion: a critical conceptual review. Health Psychol Rev 2021 Mar;15(1):34-50. [doi: 10.1080/17437199.2019.1706616] [Medline: 31900043]

68. Goodyear VA, Kerner C, Quennerstedt M. Young people's uses of wearable healthy lifestyle technologies; surveillance, self-surveillance and resistance. Sport, Education and Society 2017 Sep 22;24(3):212-225. [doi: $10.1080 / 13573322.2017 .1375907]$

69. Attig C, Franke T. Abandonment of personal quantification: A review and empirical study investigating reasons for wearable activity tracking attrition. Computers in Human Behavior 2020 Jan;102:223-237. [doi: 10.1016/j.chb.2019.08.025]

70. Achatz J, Selke S, Wulf N. Adjusting Reality. The Contingency Dilemma in the Context of Popularised Practices of Digital Self-Tracking of Health Data. Historical Social Research/Historische Sozialforschung 2021 Jan;46(1):206-229.

71. Baretta D, Bondaronek P, Direito A, Steca P. Implementation of the goal-setting components in popular physical activity apps: Review and content analysis. Digital Health 2019 Jul 16;5:1-10 [FREE Full text] [doi: 10.1177/2055207619862706] [Medline: 31360535]

72. Brower J, LaBarge MC, White L, Mitchell MS. Examining Responsiveness to an Incentive-Based Mobile Health App: Longitudinal Observational Study. J Med Internet Res 2020 Aug 10;22(8):e16797 [FREE Full text] [doi: 10.2196/16797] [Medline: 32773371]

73. Lewis ZH, Swartz MC, Lyons EJ. What's the Point?: A Review of Reward Systems Implemented in Gamification Interventions. Games Health J 2016 Apr;5(2):93-99. [doi: 10.1089/g4h.2015.0078] [Medline: 26812253]

74. Williamson C, Baker G, Mutrie N, Niven A, Kelly P. Get the message? A scoping review of physical activity messaging. Int J Behav Nutr Phys Act 2020 Apr 15;17(1):51 [FREE Full text] [doi: 10.1186/s12966-020-00954-3] [Medline: $\underline{32295613}$ ]

75. Adjerid I, Loewenstein G, Purta R, Striegel A. Gain-Loss Incentives and Physical Activity: The Role of Choice and Wearable Health Tools. Management Science 2021 May 28:1-19. [doi: 10.1287/mnsc.2021.4004] 
76. Niforatos E, Tran C, Pappas I, Giannakos M. Goalkeeper: A Zero-Sum Exergame for Motivating Physical Activity. 2021 Aug 26 Presented at: Human-Computer Interaction - INTERACT 2021; 18th IFIP TC 13 International Conference; August 30 to September 3, 2021; Bari, Italy p. 65-86. [doi: 10.1007/978-3-030-85613-7 5]

77. Page EJ, Massey AS, Prado-Romero PN, Albadawi S. The Use of Self-Monitoring and Technology to Increase Physical Activity: A Review of the Literature. Perspect Behav Sci 2020 Aug 10;43(3):501-514. [doi: 10.1007/s40614-020-00260-0]

78. McEwan D, Harden SM, Zumbo BD, Sylvester BD, Kaulius M, Ruissen GR, et al. The effectiveness of multi-component goal setting interventions for changing physical activity behaviour: a systematic review and meta-analysis. Health Psychol Rev 2016;10(1):67-88. [doi: 10.1080/17437199.2015.1104258] [Medline: 26445201]

79. Phillips LA, Gardner B. Habitual exercise instigation (vs. execution) predicts healthy adults' exercise frequency. Health Psychol 2016 Jan;35(1):69-77. [doi: 10.1037/hea0000249] [Medline: 26148187]

80. Lally P, Wardle J, Gardner B. Experiences of habit formation: a qualitative study. Psychol Health Med 2011

Aug;16(4):484-489. [doi: 10.1080/13548506.2011.555774] [Medline: 21749245]

81. Gardner B, Rebar AL, Lally P. A matter of habit: Recognizing the multiple roles of habit in health behaviour. Br J Health Psychol 2019 May;24(2):241-249. [doi: 10.1111/bjhp.12369] [Medline: 30945793]

82. Chew L, Tavitian-Exley I, Lim N, Ong A. Can a multi-level intervention approach, combining behavioural disciplines, novel technology and incentives increase physical activity at population-level? BMC Public Health 2021 Jan 11;21(1):120 [FREE Full text] [doi: 10.1186/s12889-020-10092-x] [Medline: $\underline{\text { 33430835] }}$

\author{
Abbreviations \\ BMI: body-mass index \\ BREQ-3: Behavioral Regulation in Exercise Questionnaire 3 \\ HPB: Health Promotion Board \\ HPFI: Health Promoting Financial Incentive \\ IPAQ-SF: International Physical Activity Questionnaire Short Form \\ mHealth: mobile health \\ NSC: national steps challenge
}

\author{
Edited by A Mavragani; submitted 23.09.21; peer-reviewed by G Jerome; comments to author 15.10.21; revised version received \\ 15.11.21; accepted 10.12.21; published 25.01.22 \\ Please cite as: \\ Gorny AW, Chee WCD, Müller-Riemenschneider F \\ Active Use and Engagement in an mHealth Initiative Among Young Men With Obesity: Mixed Methods Study \\ JMIR Form Res 2022;6(1):e33798 \\ URL: https://formative.jmir.org/2022/1/e33798 \\ doi: $10.2196 / 33798$ \\ PMID:
}

(CAlexander Wilhelm Gorny, Wei Chian Douglas Chee, Falk Müller-Riemenschneider. Originally published in JMIR Formative Research (https://formative.jmir.org), 25.01.2022. This is an open-access article distributed under the terms of the Creative Commons Attribution License (https://creativecommons.org/licenses/by/4.0/), which permits unrestricted use, distribution, and reproduction in any medium, provided the original work, first published in JMIR Formative Research, is properly cited. The complete bibliographic information, a link to the original publication on https://formative.jmir.org, as well as this copyright and license information must be included. 